$\mathbf{T}$ he 2013 TAPPI International Conference on Nanotechnology for Renewable Materials will be held on June 24-27, 2013, at KTH Royal Institute of Technology, in Stockholm, Sweden. Chaired by Bruce Lyne, KTH; Phil Jones, IMERYS; and Ulla Forsström,
VTT, the conference will focus on nanocellulosics and nanocomposites, applications of renewable nanomaterials, nanocellulose-organic/inorganic hybrids and self-assembly of nanomaterials, nanotech coatings and novel nano-enabled functionalities, character- ization and International standards for nanocellulose, and current understanding and critical gaps in environmental, health, and safety issues for nanomaterials. The conference is endorsed by the Materials Research Society.

\title{
MC11 to be held in UK in July 2013 \\ www.rsc.org
}

T he Royal Society of Chemistry will produce the 11th International Conference on Materials Chemistry (MC11) on July 8-11, 2013, at the University of Warwick, United Kingdom. The main themes will focus on biomaterials, energy materials, environmen- tal materials, and electronic, magnetic, and optical materials. The format includes plenary lectures as well as a keynote speaker for each symposium followed by contributed speakers, and two poster sessions. Confirmed plenary and keynote speakers can be seen at the conference website linked from www.rsc.org. Pre-registration rates are available until May 10, 2013. The conference is endorsed by the Materials Research Society.

\section{Conference on physical metallurgy of steels to be streamed live in July 2013 www.msm.cam.ac.uk/apms}

T The conference Adventures in the Physical Metallurgy of Steels, to be held on July 23-25, 2013, at the University of Cambridge, will be made available live online free of charge to 100 locations around the world. Twenty-five speakers will be selected accord- ing to the level of adventure and risk in their work, with no parallel sessions. The conference will accommodate up to 75 additional attendees. The presentations will be published as a special issue of Materials Science and Technology with independent refereeing through the journal's usual editorial process. The conference, hosted by the Phase Transformations and Complex Properties research group in the Department of Materials Science and Metallurgy at Cambridge, is endorsed by the Materials Research Society.

\section{SMMIB 2013 to be held in Turkey in September}

www.smmib2013.net

T The 18th International Conference on Surface Modification of Materials by Ion Beams will be held on September 15-20, 2013, in Kusadasi, Turkey. Chaired and co-chaired by Ahmet Öztarhan and Emel Sokullu Urkaç, respectively, from Ege University, the conference will focus on phenomena, processes, and techniques; fundamental studies of ion-beam processing; applications; and emerging techniques and equipment. The format includes oral and poster presentations and an equip- ment exhibit. Proceedings will be published in a special issue of Applied Surface Science.

Invited speakers include Nobel laureate Andre Geim of the University of Manchester, Paul F.A. Alkemade of the Delft University of Technology, John Baglin of IBM Almaden Research Center in California, Paul K. Chu of City University of Hong Kong, Ryosuke Ikeguchi of the Kobe City Medical Center General Hospital in Japan, Daryush Ila of Fayetteville State University, Tapo- brata Som of the Institute of Physics in Bhubaneswar, and Ronghua Wei of Southwest Research Institute headquartered in Texas.

The deadline for abstracts and early registration is April 30, 2013.

More information can be accessed at the website www.smmib2013.net, by email to the chair or co-chair at aoztarhan@smmib2013.net oremel@ smmib2013.net, or at info@devajans. com. The conference is endorsed by the Materials Research Society. 